\title{
Cost-benefit analysis
}

\author{
Ray Robinson
}

This is the fifth in a series of articles that describes the ways in which methods of economic evaluation may be used to assess the economic costs and consequences associated with different forms of health care intervention.
Institute for Health Policy Studies, Faculty of Social Sciences, The University, Southampton SO9 5NH Ray Robinson, professor and director
Cost-benefit analysis is probably the most comprehensive method of economic evaluation available and it can be applied in two ways. The human capital approach means that the value of people's contributions is linked to what they are paid. The approach based on individuals' observed or stated preference means that their personal valuations are placed on an activity by assessing how much money they are prepared to accept for an increased risk or to pay for a particular service. Each method has its disadvantages and the most successful that has been devised so far is the "willingness to pay" (stated preference) approach, though the response to this is to a large extent dependent on the income of the person being questioned. There are still problems with its application, however, so its usefulness is limited.

Cost-benefit analysis is the most comprehensive and theoretically sound form of economic evaluation and it has been used as an aid to decision making in many different areas of economic and social policy in the public sector during the last 50 years. There are numerous textbooks dealing with the theory and practice of the general approach. ${ }^{1-3}$

The main difference between cost-benefit analysis and other methods of economic evaluation that were discussed earlier in this series is that it seeks to place monetary values on both the inputs (costs) and outcomes (benefits) of health care. Among other things this enables the (monetary) returns on investments in health to be compared with the returns obtainable from investments in other areas of the economy. Within the health sector itself, the attachment of monetary values to outcomes makes it possible to say whether a particular procedure or programme offers an overall net gain to society in the sense that its total benefits exceed its total costs. Cost-effectiveness and costutility analysis do not do this because they measure costs and benefits in different units.

Devising ways in which complex outcomes of health care can be reduced to a single monetary measure is not easy and is the main reason why cost-effectiveness and cost-utility analysis have been relied on more often in the health care sector. None the less there have been a number of approaches which over the years have sought to place monetary values on the benefits that arise from health care programmes. These may be divided into two main categories: the human capital approach and approaches based on individuals' observed or stated preferences.

\section{Human capital approach}

Early approaches to benefit valuation were commonly based on the concept of "human capital." This concept is designed to convey the fact that human beings are similar to capital equipment (at least as far as their working lives are concerned) in the sense that they can be expected to yield a flow of productive activity in future years. If the value of this activity in any period of time is assumed to be equal to the individual person's rate of pay, then the benefits of health care can be measured in terms of the future flow of income that would otherwise have been forgone because of ill health. Because these calculations involve adding up a stream of income that accrues over a number of different years, the sum in each year must be time-discounted to take account of the precise time profile of benefits (methods of time discounting and debates surrounding this practice were discussed in the second and third articles in this series).

The human capital approach has been applied in the valuation of health benefits in cases of both avoidable morbidity and mortality. There have, however, been various criticisms. As one of the first attempts to place monetary values on avoided mortality it led to monetary values being placed on human life and many people have strong ethical objections to this. In contrast, most economists think that implicit valuations are placed on human lives in a whole range of decisions about allocation of resources in the public sector and the cost-benefit approach is simply being explicit about the process. ${ }^{45}$

Other criticisms have centred on the use of rates of pay as a measure of value. Economic theory suggests that productivity is accurately measured only by rates of pay when certain conditions in the labour market are met. The widespread existence of restrictive practices and other forms of imperfections in the labour market means that these conditions often do not apply in practice. At the same time, valuing benefits in terms of rates of pay neglects the health benefits that accrue to people who are not employed-for example, non-working wives and retired people. It also ignores the non-financial costs of pain, suffering, and grief which are often associated with illness. But, from an economist's perspective, the main criticism of the approach is that it is not based on an individual person's valuations of benefits. Indeed, a third party view is taken about people's "worth" to society in terms of their productive potential. This viewpoint is inconsistent with the prevailing view among economists that the individual person is the best judge of his or her own welfare.

\section{Individuals' observed or stated preferences}

The observed preferences approach involves observing individuals' behaviour and using these observations as a basis for valuing benefits. One method of doing this is to observe their behaviour towards risk and then to estimate the personal valuations implicit in this behaviour. Some people accept "danger money" for undertaking work with an increased risk of injury or death-for example, deep-sea divers. Others spend money on cars with enhanced safety features to reduce the risk of injury or death. When the extra income received or expenditure undertaken is compared with the change in the degree of risk associated with a particular activity, it becomes possible to establish the personal valuations implicit in observed behaviour. Converting valuations associated with small changes in risk into full life valuation is not straightforward, but various techniques associated with "scaling risks" have been developed. ${ }^{6}$ On a practical level, however, one of the main disadvantages of this approach is the limited number of situations under which attitudes towards risk can be observed and measured. This has led to the 


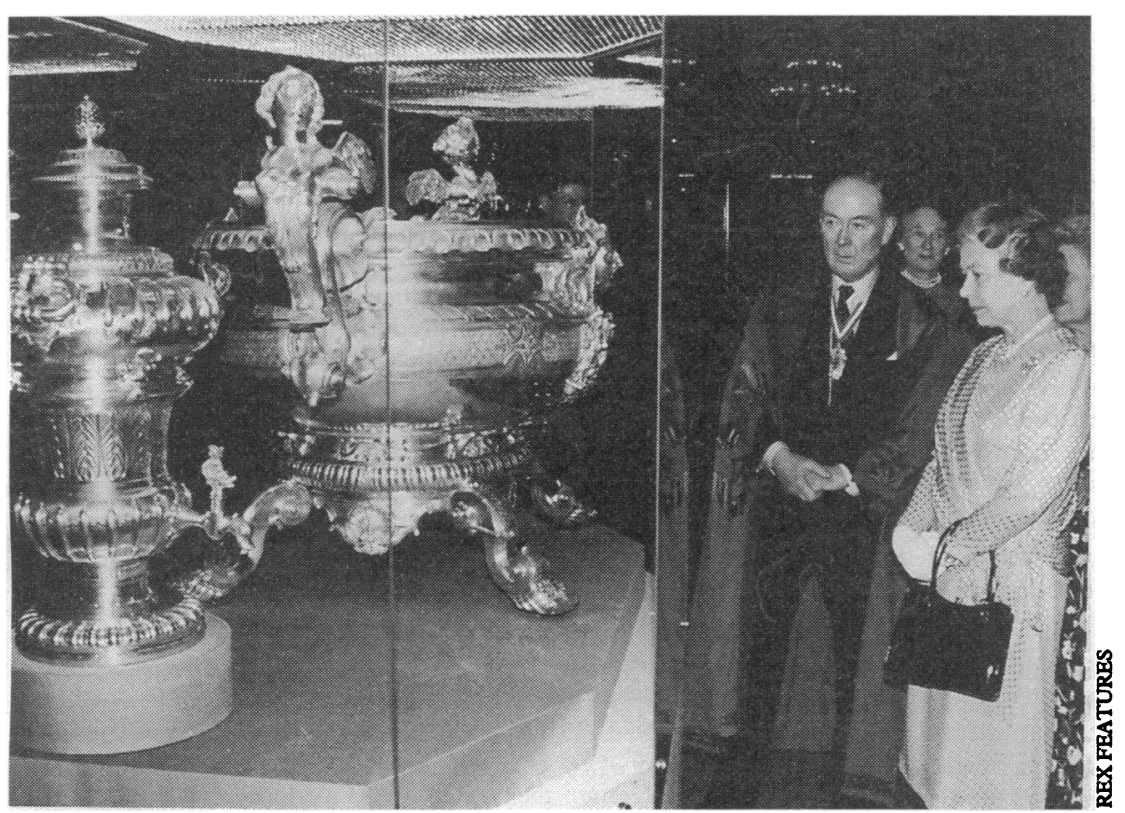

Value is in the eye of the beholder
More recently, Thompson used willingness to pay methods to value the effect of a hypothetical cure on their state of health in 247 patients with rheumatoid arthritis who were already enrolled in a randomised controlled drug trial. ${ }^{11}$ During interviews, respondents were asked to think about the ways in which arthritis affected their lives and their families. They were then told to assume that there was a complete cure for their disease and asked how much they would be willing to pay for it. The precise question that they were asked was: "What percent of your families' (ie household) total monthly income would you be willing to pay on a regular basis for a complete cure for arthritis?" Consistency of answers was checked by a follow up question about how the family would manage to live on the remaining amount.

Using these methods, Thompson obtained a $96 \%$ response and $84 \%$ of the responders gave answers that met predetermined criteria for plausibility. The results indicated that the average responder was willing to pay $22 \%$ of their household income to secure a cure for arthritis. This proportion did not vary with income.

In another study, Johannesson, Jonsson, and Borgquist 11th Nordic Health Economists' Study Group Meeting, Stockholm, 27-28 August 1990) examined willingness to pay for antihypertensive therapy. They achieved a response rate of $67 \%$ from an elderly population (mean age 64.4 years) comprising 481 patients at a primary health care centre. A particular focus of this study was an investigation of the relative merits of an open ended questionnaire compared with one using discrete yes/no questions. The authors concluded that open ended questions do not work well in willingness to pay postal surveys. Discrete questions, on the other hand, led to a lower nonresponse rate and provided respondents with an easier valuation task. This approach indicated that people would be willing to pay between $\mathrm{SKr} 2500$ and SKr 5000/year (about $£ 225-£ 450$ ) for antihypertensive therapy. The authors also concluded that although the results should be interpreted with caution, they indicated a large potential application for willingness to pay methods in the field of preventive health care.

Two recent studies carried out in the United Kingdom were by Rushby (JA Rushby. Paper presented to the Health Economists' Study Group, July 1991) and Donaldson. ${ }^{12}$ Rushby investigated willingness to pay for improvements in the quality of life offered by heart pacemakers. Respondents were asked to state their maximum willingness to pay to be free of specified symptoms associated with heart disease (shortness of breath, chest pain, dizziness, fainting, and palpitations). Groups of respondents included those with personal .experience of the symptoms, those with experience of caring for patients, and those with no more experience of the symptoms than the general population. All groups were, however, asked to base their answers on hypothetical cases rather than current experience. The answers indicated that the mean willingness to pay varied from $£ 45.50$ /month for heart palpitations to $£ 70.67 /$ month for chest pain. are a number of other forms of strategic and complian bias which must be guarded against whichever approach is used. ${ }^{9}$

Applications of the willingness to pay approach to health care are still relatively rare, but some interesting studies have been undertaken. For example, in an early application of the approach, Acton investigated willingness to pay for mobile coronary care units that would reduce the risk of death after a heart attack. ${ }^{10}$ Among other things, this study looked at a respondent's personal willingness to pay for a programme, given various probabilities of heart attack and death, in comparison with their willingness to pay for a community programme. Not surprisingly, perhaps, willingness to pay was greater for perceived personal benefits than it was for community benefits. 
Donaldson applied willingness to pay in an attempt to value the benefits of continuing care accommodation for elderly people. ${ }^{12}$ The aim was to compare NHS nursing homes with NHS hospital accommodation. A distinctive feature of the study was that relatives of respondents not the residents themselves were asked how much they thought the government should be willing to pay for the respective accommodation; $71 \%$ of respondents provided valuations that could be used in the analysis and their answers indicated a clear preference for nursing home accommodation over hospital accommodation when the total willingness to pay of the two options was compared with their respective costs.

In a recent review of the application of willingness to pay studies, Morrison and Gyldmark argued that three criteria must be met if use of the approach is to be valid. ${ }^{13}$ Firstly, given the uncertainty surrounding individual subjects' needs for health care, willingness to pay questions should ask how much a person is willing to pay as an insurance premium so that a given service would be available if it is needed. Secondly, expectations should be expressed in terms of probabilities; that is, what is the probability of needing treatment and of its success? Thirdly, representative samples of the population are necessary to establish the total willingness to pay of the relevant population. They concluded that few of the studies carried out to date meet these criteria and that there are other methodological issues that require attention, among which is the link between willingness to pay and income.

\section{Income and monetary valuation of benefits}

Valuing the benefits of health care interventions in terms of willingness to pay raises the problem that the amount people are willing to pay is often positively related to their level of income. The fact that a rich person is willing to pay $£ 40 /$ week for a drug whereas a poor person is willing to pay only $£ 10 /$ week is likely to reflect the value each of them attaches to money itself as well as the benefits of the drug to health.

This is a problem that bedevils all attempts to value benefits in monetary terms, both inside and outside the health sector and it occurs when payment is actually made as well as when it is based on willingness to pay surveys. In some cases attempts have been made to overcome the problem by "weighting" benefits according to the income group of recipients with lower income groups receiving larger weights, but this raises many practical problems in addition to the obvious one of calculating the appropriate scale of weights. Another approach is to take willingness to pay figures at their face value if the programme under consideration requires only small amounts of expenditure in relation to a person's total income. If this is done distortions that result from different valuations of money itself are likely to be minimised.

\section{Conclusion}

Cost-benefit analysis is the most comprehensive form of economic evaluation. By assigning monetary values to both costs and benefits, it offers the potential for comparisons between a wide range of programmes both within the health sector and between the health and non-health sectors. As far as its application within

\section{Summary}

- Cost-benefit analysis places monetary values on both the inputs (costs) and the outcomes (benefits) of health care

- Early methods of valuation of benefits were based on the human capital approach in which benefits are valued in terms of productivity gains. Rates of pay are used as a measure of productivity

- Recent approaches have adopted the more theoretically sound practice of basing valuations on peoples' observed or stated preferences

- Stated preferences are usually based on willingness to pay; the value people attach to health care outcomes is established by asking them how much they would be prepared to pay to obtain the benefits or avoid the costs of illness

- The dependence of willingness to pay on a person's income does, however, create a difficulty because answers may reflect the value people attach to money itself as well as their valuation of the benefits of health care

- Despite their theoretical superiority, willingness to pay studies are still relatively rare. Their application in the immediate future is likely to be most appropriate in the case of, for example, pharmaceutical products where qualitative health gains are achievable, where payments are small in relation to income, and where people are familiar with cash transactions

the health sector is concerned, it is a more powerful technique than either cost-effectiveness or cost-utility analysis. Among other things, it enables people to express the benefits of health care in terms of their valuations of the quantity of life, its quality, and any other dimension that they feel is important. And all of these diverse benefits are expressed in terms of a single common unit of measurement.

Early methods of obtaining valuations based on the human capital approach have been largely superseded by more theoretically sound methods based on individuals' stated preferences, but a number of theoretical and practical problems remain and applications of the approach have been relatively uncommon. In the immediate future its application is likely to be restricted to those areas in which small improvements in the state of health are attainable, in which payments are relatively small in relation to income, and in which patients have some familiarity with cash paymentsfor example, pharmaceutical products that offer improvements in the quality of life.

1 Pearce DW. Cost-benefit analysis. 2nd ed. London: Macmillan, 1983.

2 Mishan EJ. Cost-benefit analysis. 4th ed. London: Unwin Hyman, 1988.

3 Walshe G, Daffern P. Managing cost benefit analysis. London: Macmillan, 1990.

4 Jones-Lee MW. The value of life. An economic analysis. London: Martin Robertson, 1976.

5 Mooney GH. The valuation of human life. London: Macmillan, 1977.

6 Mooney GH. Human life and suffering. In: Pearce DW, editor. The valuation of social cost. London: George Allen \& Unwin, 1978.

7 Mitchell RC, Carson RT. Using surveys to value public goods. Washington, DC Resources for the Future, 1989.

8 Commission on the third London airport. Report. London: HMSO, 1971.

9 Johannesson M, Jonsson B. Economic evaluation in health care: is there a role for cost benefit analysis? Health Policy 1991;17:1-23.

10 Acton JP. Evaluating public programs to save lives: the case of heart attacks. Santa Monica: Rand, 1973.

11 Thompson MS. Willingness to pay and accept risks to cure chronic disease. Am $\mathcal{F}$ Public Health 1986;76:392-6.

12 Donaldson D. Willingness to pay for publicly-provided goods. fournal of Health Economics 1990;9:103-18.

13 Morrison GC, Gyldmark M. Appraising the use of contingent valuation. Health Economics 1992;1:233-43. 